\title{
A retrospective study of the real-life utilization and effectiveness of ranibizumab therapy for neovascular age-related macular degeneration in the UK
}

\author{
This article was published in the following Dove Press journal: \\ Clinical Ophthalmology \\ 13 January 2016 \\ Number of times this article has been viewed
}

\author{
Philip Hykin' \\ Usha Chakravarthy² \\ Andrew Lotery ${ }^{3}$ \\ Martin McKibbin ${ }^{4}$ \\ Jackie Napier ${ }^{5}$ \\ Sobha Sivaprasad ${ }^{1,6}$ \\ On behalf of the AURA \\ Study Group \\ 'National Institute for Health \\ Research Biomedical Research Centre \\ in Ophthalmology, Moorfields Eye \\ Hospital, London, UK; ' ${ }^{2}$ nstitute \\ of Clinical Science, The Queen's \\ University of Belfast, Belfast, UK; \\ ${ }^{3}$ Clinical and Experimental Sciences, \\ Faculty of Medicine, University of \\ Southampton, Southampton, UK; ${ }^{4}$ Eye \\ Clinic, St James's University Hospital, \\ Leeds, UK; ${ }^{5}$ Bayer HealthCare \\ Pharmaceuticals AG, Newbury, \\ Berkshire, UK; ${ }^{6}$ Ophthalmology \\ Department, King's College Hospital, \\ London, UK
}

Correspondence: Sobha Sivaprasad Ophthalmology Department, King's College Hospital, Denmark Hill, London SE5 9RS, UK

Tel +442032994548

Fax +442032993738

Email senswathi@aol.com
Purpose: AURA was an international, retrospective, observational study that monitored the real-life use and effectiveness of ranibizumab injections in patients with neovascular age-related macular degeneration (nAMD). This paper reports the findings from the UK.

Methods: Patients who started treatment with ranibizumab between January 1, 2009, and August 31, 2009, and had documented follow-up to the end of their treatment and/or monitoring or until August 31, 2011, were retrospectively monitored; the diagnosis and subsequent decision to treat was made by the patient's own physician. Assessments included the change in visual acuity (standardized letter count) during the first and second years after start of ranibizumab therapy and resource utilization.

Results: Four hundred and ten patients from 13 UK centers were analyzed. The mean (standard deviation [SD]) letter score at baseline was 55.0 (17.8). The mean (SD) change in visual acuity from baseline was $+6.0(15.4)$ letters at year 1 and +4.1 (16.9) at year 2. Most of the patients $(86.6 \%)$ completed a 3-month loading phase; the visual improvements were numerically higher in these patients. Over 2 years, the mean (SD) number of clinic visits and injections was 18.4 (5.0) and 9.0 (4.7), respectively. Resource use and visual acuity gains were greater than those observed in the global population, which included other countries enrolled in AURA (Canada, France, Germany, Ireland, Italy, the Netherlands, and Venezuela). When patients were stratified according to severity of nAMD (based on letter count at baseline), the mean change in visual acuity score at years 1 and 2 was also higher for the UK than for the global population across all subgroups.

Conclusion: Monitoring and treatment rates were high in the UK, resulting in better visual acuity outcomes compared with other included countries. This suggests that translation of clinical study outcomes into real-life settings is achievable, but at the expense of higher resource utilization than is currently the norm in most developed countries.

Keywords: neovascular or wet age-related macular degeneration, anti-vascular endothelial growth factor

\section{Introduction}

The current standard of care for neovascular age-related macular degeneration (nAMD) is treatment with agents (such as ranibizumab) that inhibit vascular endothelial growth factor (VEGF), a potent angiogenic mediator associated with age-dependent choroidal neovascularization. ${ }^{1}$ Ranibizumab was approved for use in nAMD largely due to the findings from two pivotal clinical studies. ${ }^{2,3}$ In these studies, monthly ranibizumab $(0.3$ or $0.5 \mathrm{mg})$ was shown to be superior to sham or photody- 
namic therapy for the 12-month primary efficacy outcome, and visual and anatomical benefits were sustained over a 24-month follow-up. ${ }^{2-4}$ Based on these studies, monthly dosing with ranibizumab was recommended. ${ }^{5}$ However, this approach can be unsustainable in many clinical practices. Less frequent dosing is now the norm, and the label for all the currently available anti-VEGF agents recommends an initial loading phase followed by as-needed (PRN) dosing with frequent monitoring. 5,6

However, it is acknowledged that PRN or quarterly dosing may be less effective compared with monthly dosing, and optimal regimens need to be established..$^{7-11}$ Some studies show that the visual benefit declines during the maintenance phase despite an initial marked improvement in acuity at the completion of the loading phase. ${ }^{7,8,10,11}$ In contrast, the SUSTAIN study found that ranibizumab PRN was comparable with monthly dosing. ${ }^{12}$

The AURA study was undertaken to monitor ranibizumab use and treatment outcomes in a real-life setting. AURA was a large, retrospective study conducted in eight countries (Canada, France, Germany, Ireland, Italy, the Netherlands, the UK, and Venezuela) that evaluated the real-life clinical use of ranibizumab treatment for patients with nAMD who were diagnosed and treated by their own physicians. ${ }^{13}$ In the global population (all eight included countries), there was a mean increase in visual acuity of +2.4 letters during year 1 , which decreased to +0.6 letters during year 2 . Patients received approximately seven injections over a 2-year period, but there was variability between countries. The findings also indicated that monitoring strategies and retreatment frequencies varied between countries, which may explain the poorer visual outcomes in the overall AURA population. The aim of the present report is to describe the outcomes of the UK cohort of AURA and to compare with the global AURA cohort (Canada, France, Germany, Ireland, Italy, the Netherlands, and Venezuela).

\section{Materials and methods}

\section{Study design and participants}

The study design has been reported elsewhere. ${ }^{13}$ In brief, patients who were diagnosed with nAMD and given ranibizumab injections during January 1, 2009 to August 31, 2009 were eligible; the diagnosis and subsequent decision to treat was made by the patient's own physician. For inclusion, patients were required to have received one or more ranibizumab injections with documented follow-up to the end of their treatment and/or monitoring, or until August 31, 2011, whichever came first (Figure S1). Patients who switched to bevacizumab or pegaptanib sodium, but received ranibizumab at some point, remained in the study. Only one eye was included per patient, which was defined as the eye treated at the start of ranibizumab therapy. In patients with bilateral disease, the eye with the worst visual acuity was included. Patients taking part in an investigational study of any other drug or device were excluded. Approval from the country-specific independent ethics committees or institutional review boards was received based on the requirements of local law and/or regulations, and written consent was obtained from each patient prior to inclusion. We certify that all applicable institutional and governmental regulations concerning the ethical use of human volunteers were followed during this research. This paper reports the findings from the UK cohort only, but makes explicit comparisons with the global results.

\section{Assessments}

All data, including demographics, were collected retrospectively from patients' medical records (paper or electronic), which included results from examinations performed during routine clinical practice. The primary assessment was the mean change in visual acuity over the 2-year period (with key assessments at year 1 [day 360] and year 2 [day 720]) after the start of ranibizumab treatment. As the study was observational, visual acuity was measured using a variety of vision charts, but was converted to a standardized visual acuity scoring system (letter count). The conversion chart used is provided in the online Supplementary material for the primary manuscript. ${ }^{13}$ Secondary assessments included resource utilization during the 2-year period (ie, the number of clinic visits, use of optical coherence tomography [OCT] and visual acuity tests, and the number of injections).

\section{Statistical analysis}

The study was explorative, and all the analyses are descriptive. The mean change in visual acuity over the 2-year period was calculated for patients who received one or more doses of ranibizumab treatment and had one or more post-baseline assessments of visual acuity for the treated eye. This was defined as the effectiveness analysis set, and it was estimated that a guiding sample size of 399 subjects per country was required to estimate the change from baseline in the standardized visual acuity score within a $95 \%$ confidence interval (CI) of \pm 1.5 letters. Mean change in visual acuity was assessed using a last observation carried forward (LOCF) analysis to account for missing data. Secondary assessments were 
analyzed using frequency tables or summary statistics and were also performed using the effectiveness analysis set.

\section{Results}

\section{Participants}

A total of 774 patients were screened, and 461 of these were enrolled from 13 centers in the UK. A total of 313 patients were excluded for the following reasons: participation in an investigational study ( $\mathrm{n}=40$ ), no diagnosis of nAMD $(\mathrm{n}=3)$, no informed consent form signed $(\mathrm{n}=257)$, and start of ranibizumab therapy outside inclusion dates $(n=13)$. Of the enrolled patients, 410 received one or more doses of ranibizumab, had one or more post-baseline measurements of visual acuity for the treated eye, and were included in the effectiveness analysis set (thus meeting the prespecified sample size of 399 subjects).

The baseline characteristics of patients included in the effectiveness analysis sets in the UK and global cohorts are shown in Table 1. The cohorts were well-matched with regard to age, sex, OCT volume (center point thickness), and mean visual acuity (letter count) at baseline. Although the aim of the study was to follow patients receiving ranibizumab treatment, five patients received at least one

Table I Patient demographics at baseline in the UK and global population (effectiveness analysis set)

\begin{tabular}{|c|c|c|}
\hline & $\begin{array}{l}\text { UK, } \\
n=410\end{array}$ & $\begin{array}{l}\text { Global, } \\
N=2,227\end{array}$ \\
\hline \multicolumn{3}{|l|}{ Age at treatment start, years ${ }^{\mathrm{a}}$} \\
\hline Mean (SD) & $77.7(7.5)$ & $76.9(8.2)$ \\
\hline \multicolumn{3}{|l|}{ Sex } \\
\hline Male, n (\%) & $163(39.8)$ & $878(39.4)$ \\
\hline Female, n (\%) & $247(60.2)$ & I,349 (60.6) \\
\hline \multicolumn{3}{|l|}{ Eye affected by nAMD } \\
\hline Right, n (\%) & $166(40.5)$ & $956(42.9)$ \\
\hline Left, n (\%) & $162(39.5)$ & $937(42.1)$ \\
\hline Right and left, n (\%) & $82(20.0)$ & $334(15.0)$ \\
\hline \multicolumn{3}{|c|}{ OCT volume - thickness center point, $\mu \mathrm{m}^{\mathrm{b}}$} \\
\hline Mean (SD) & $336.5(114.3)$ & $334.4($ (I I3.6) \\
\hline \multicolumn{3}{|l|}{ Visual acuity ranges, letters ${ }^{c}$} \\
\hline$\geq 65, \mathrm{n}(\%)$ & I 37 (33.4) & $858(38.5)$ \\
\hline$\geq 55-<65$ letters, $n(\%)$ & I0I (24.6) & $435(19.5)$ \\
\hline$\geq 35-<55$ letters, $n(\%)$ & $132(32.2)$ & $645(29.0)$ \\
\hline$<35$ letters, $n(\%)$ & $38(9.3)$ & $209(9.4)$ \\
\hline Missing, n (\%) & $2(0.5)$ & $80(3.6)$ \\
\hline \multicolumn{3}{|l|}{ Visual acuity, letters } \\
\hline Baseline, mean (SD) & $55.0(17.8)$ & $55.4(18.4)$ \\
\hline Year I, mean (SD) & $60.8(20.0)$ & $57.3(20.6)$ \\
\hline Year 2, mean (SD) & $59.0(20.9)$ & $55.4(21.5)$ \\
\hline
\end{tabular}

Notes: ${ }^{a} \mathrm{n}=2,185$ (global); ${ }^{b} \mathrm{n}=197$ (UK) and $\mathrm{n}=690$ (global); 'patients included in effectiveness analysis set based on mean letter score at baseline.

Abbreviations: nAMD, neovascular age-related macular degeneration; OCT, optical coherence tomography; SD, standard deviation. injection of bevacizumab and one patient received one injection of pegaptanib sodium. The majority of patients (99.3\% overall: $99.8 \%$ at year 1 and $99.5 \%$ at year 2 ) did not receive any treatment change. Three patients switched from ranibizumab to bevacizumab due to nonresponse $(n=2)$ and reason not known $(n=1)$.

\section{Change in visual acuity over time}

Visual acuity (letter count) improved from baseline following initiation of ranibizumab treatment, peaking at day 270 with a mean (standard deviation [SD]) gain in visual acuity of +6.5 (14.4) letters in the overall UK cohort. The mean (SD) change in visual acuity from baseline was +6.0 (15.4) letters at year 1, but there was a small decline in visual acuity over time, and the mean (SD) change was $+4.1(16.9)$ at year 2 in the UK cohort (Figure 1A).

The majority of patients in the UK cohort (355/410; $86.6 \%$ ) received a loading phase (ie, first three ranibizumab injections within 90 days). The mean change in visual acuity was greater in these patients compared with patients who did not receive a loading phase; however, a small decline in visual acuity was observed during the follow-up in both groups (Figure 1A). The mean change in visual acuity from baseline was +6.8 (15.5) letters in year 1 and +4.8 (17.1) letters in year 2 in patients receiving a loading phase, and +0.5 (13.7) and -0.2 (14.3) in patients who did not receive a loading phase.

The mean improvement in visual acuity was also greater in the UK compared with the global population (Figure 1B); there was a decline in both the UK and global populations, but this occurred earlier in the global population (from approximately day 120 onward) and was more marked. Compared with the other countries enrolled in AURA, the UK demonstrated the greatest visual acuity improvements over time, followed by the Netherlands (Figure 1C).

When patients were stratified according to severity of nAMD (based on letter count at baseline), the mean change in visual acuity score at years 1 and 2 was higher for the UK than for the global population (Figure 2). In the UK, mean (SD) improvement in visual acuity was also higher in patients with a baseline score of $<35$ letters $(+15.1$ [16.9] at year 1 and $+11.6[16.9]$ at year 2) (Figure 2).

\section{Resource utilization}

Overall, $43.4 \%$ of patients in the UK cohort received ranibizumab treatment within 2 weeks of receiving their nAMD diagnosis (Figure 3), and the mean (SD) treatment duration was 634.7 (292.4) days. In the UK cohort, the mean (SD) number of visits to the ophthalmologist was 18.4 (5.0) over 

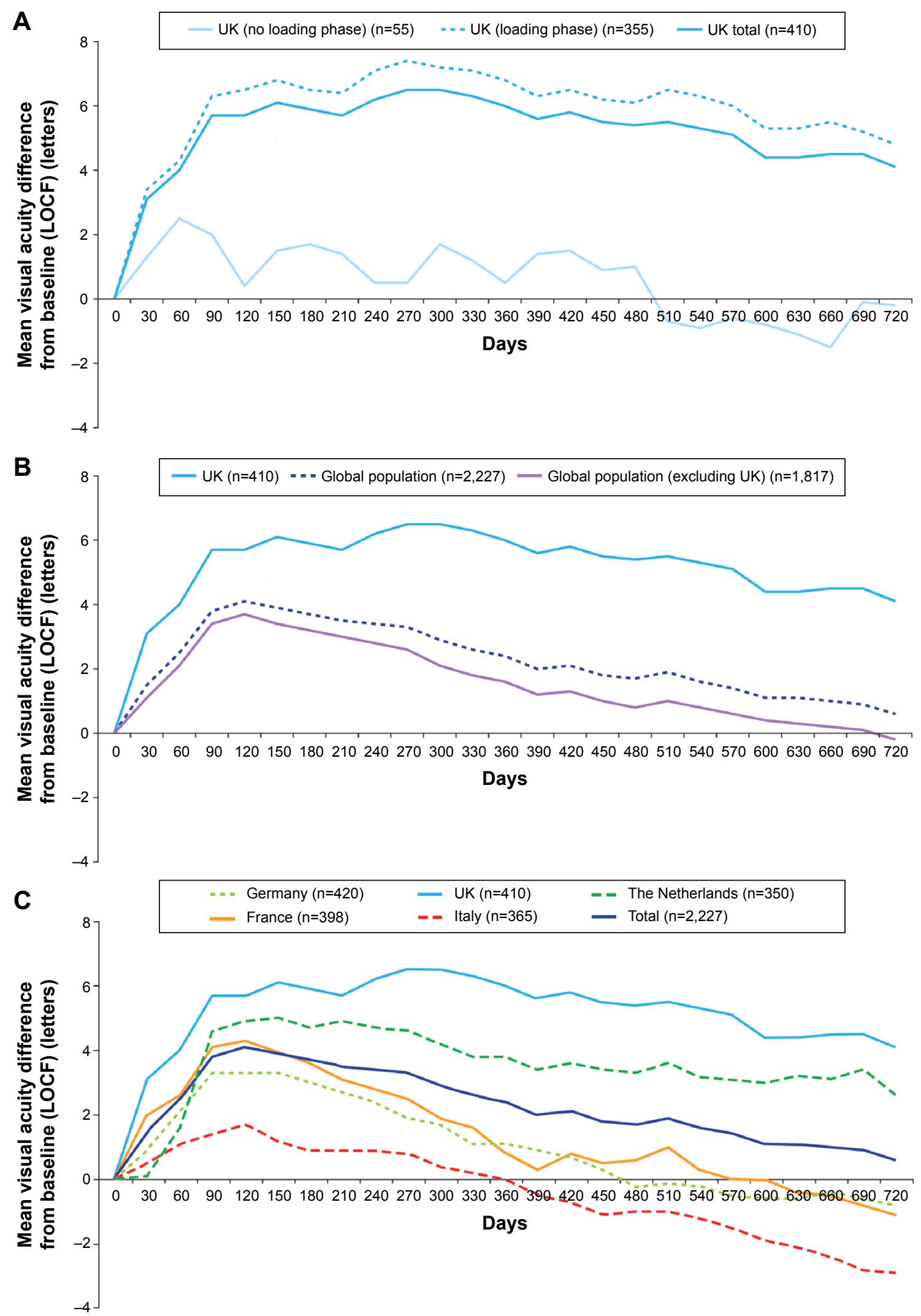

Figure I Mean change in visual acuity score (letter count) from baseline over time for the (A) UK cohort (including loading phase subgroups); (B) UK cohort versus global AURA; and (C) global AURA (country breakdown).

Notes: Data are based on effectiveness analysis set using an LOCF approach. Loading phase includes patients who received three injections over a 3-month (90-day) period. (C) Adapted by permission from BMJ Publishing Group Limited. British Journal of Ophthalmology. Multi-country real-life experience of anti-vascular endothelial growth factor therapy for wet age-related macular degeneration. Holz FG, Tadayoni R, Beatty S, et al. 2015;99(2):220-226. Copyright @ 20I5, British Medical Journal Publishing Group. ${ }^{13}$ Abbreviation: LOCF, last observation carried forward. 


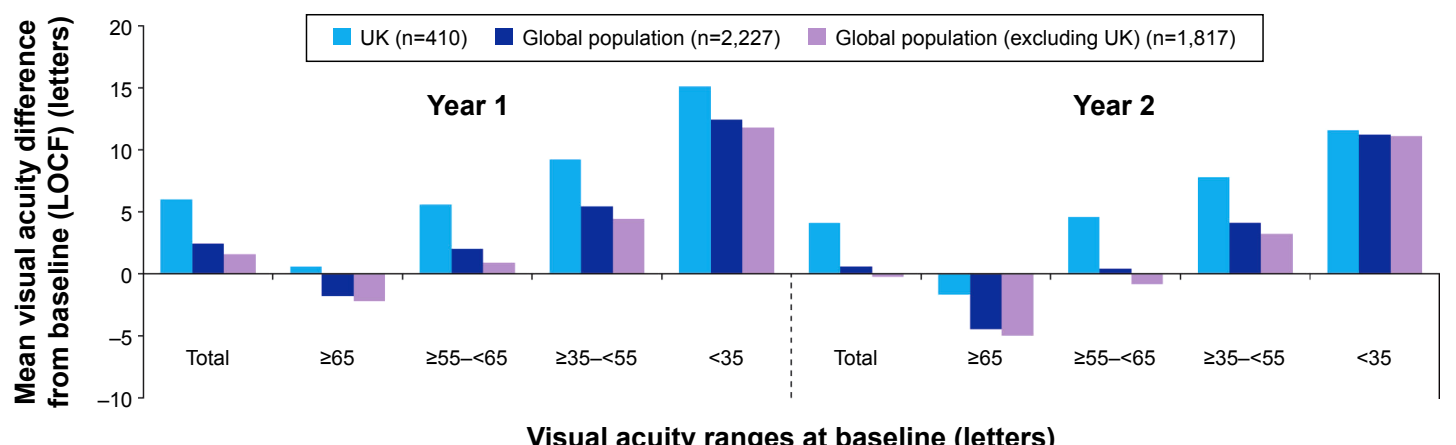

Figure 2 Change in visual acuity score at year I, year 2, and overall in the UK cohort and global AURA based on visual acuity severity (by letter score) at baseline. Note: Data are based on effectiveness analysis sets.

Abbreviation: LOCF, last observation carried forward.

the full 2-year observation period (Figure 4A). There was a higher mean (SD) number of visits in the first year (10.4 [2.2]) than in the second year (8.0 [3.3]). Similar findings were observed for the mean (SD) number of visual acuity tests (10.0 [2.4] in year 1 and 7.8 [3.3] in year 2) and OCT tests (9.2 [2.4] in year 1 and 7.4 [3.0] in year 2) (Figure 4A). Patients from the UK received a mean (SD) of 9.0 (4.7) injections during the full 2-year period (5.8 [2.4] in year 1 and 3.2 [2.8] in year 2) (Figure 4A). There were more visits, tests, and injections in the UK compared with the global population during year 1 and year 2 (Figure $4 \mathrm{~B}$ and $\mathrm{C}$ ). The mean number of injections in the UK compared with the global population (excluding the UK) was 5.8 versus 4.8 in year 1 and 3.2 versus 2.0 in year 2 .

In the global cohort, $80.2 \%(\mathrm{n}=1,786 / 2,227)$ completed a 3-month loading phase, and $19.9 \%(355 / 1,786)$ of these patients were from the UK. The mean (SD) time from the end of the loading phase to the next injection (maintenance phase) was 102.8 (121.4) days in the UK and 134.0 (141.2) days in the global cohort (excluding the UK). The mean (SD) duration between visits in the maintenance phase was 42.1 (11.7) days in the UK compared with 59.3 (51.0) in the global cohort (excluding the UK). The mean (SD) duration between

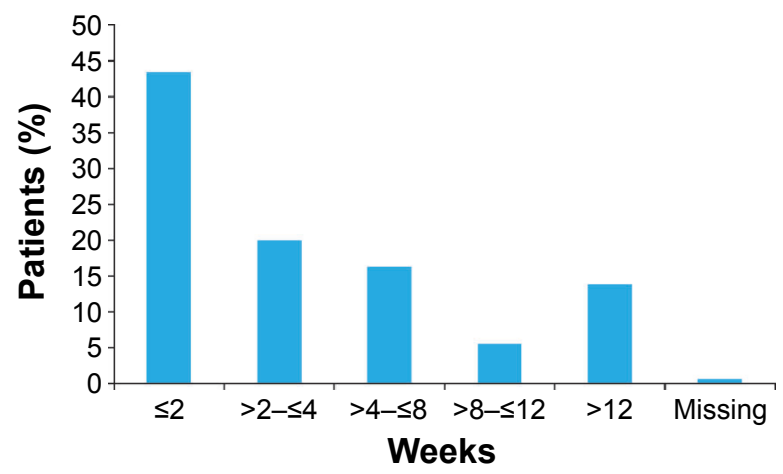

Figure 3 Time from diagnosis to treatment in the UK cohort $(n=410$; effectiveness analysis set). injections in the maintenance phase was 100.0 (80.3) in the UK cohort versus 104.1 (98.7) days in the global cohort (excluding the UK).

\section{Discontinuations (UK cohort)}

A total of 365 patients $(89.0 \%)$ completed the observation period (August 31, 2011). The remaining patients $(n=45$; $11.0 \%$ ) discontinued the study prior to this for a number of reasons, including permanent discontinuation of anti-VEGF $(n=34 ; 8.3 \%)$ (due to treatment failure [n=22], patient decision $[n=2]$, stable disease $[n=6]$, and other reason $[n=4]$, change of treating physician $(n=5 ; 1.2 \%)$, withdrawal by patient $(\mathrm{n}=1 ; 0.2 \%)$, lost to follow-up $(\mathrm{n}=1 ; 0.2 \%)$, other reason $(\mathrm{n}=3 ; 0.7 \%)$, and missing $(\mathrm{n}=1 ; 0.2 \%)$.

\section{Discussion}

Patients from AURA who were diagnosed with nAMD and treated with ranibizumab by their own ophthalmologists according to routine practice were retrospectively monitored to determine long-term effectiveness of ranibizumab from a UK perspective. Compared with the global population, the UK-specific outcomes were better and may have been achieved by higher monitoring and retreatment rates. Also, most patients in the UK $(86.6 \%)$ received a loading phase (ie, three injections within 90 days), which is more than was observed in the global population $(80.2 \%)$. The improvement in visual acuity was higher in patients who received a loading phase in both populations, but there was still decline over time, which was more marked in the global population. Patients in the UK cohort were monitored more frequently than in the global population. The mean number of ophthalmology visits in years 1 and 2 was 10.4 and 8.0 in the UK compared with 8.6 and 4.9 in the global population, respectively. The mean number of injections was also higher in the UK (5.8 in year 1 and 3.2 in year 2) compared with the global population (5.0 in year 1 and 2.2 in year 2). 



Figure 4 Resource utilization (number of visits, tests, and injections) in the (A) UK cohort ( $n=410)$; (B) global AURA ( $n=2,227)$; and (C) global AURA (excluding UK) $(\mathrm{n}=1,817)$ during the 2-year period.

Note: Data are based on effectiveness analysis sets.

These findings reflect how ranibizumab injection frequency and long-term monitoring affect visual outcomes in real-life, and are an indication of how the UK situation compares with the outcomes from other countries. Although less frequent ranibizumab dosing is not as effective as monthly dosing, four to five injections in the 9 months following a 3-month loading phase is still expected to maintain visual acuity based on clinical study outcomes. The CATT study showed that the mean change in visual acuity was +8.8 letters with monthly ranibizumab (mean number of injections was 22.4) and +6.7 letters with PRN ranibizumab (mean number of injections was 12.6) over a 2-year period. ${ }^{14} \mathrm{In}$ the ANCHOR study, ranibizumab $0.5 \mathrm{mg}$ monthly was associated with a mean change in visual acuity of +11.3 letters in year 1 and +10.7 letters in year $2 .{ }^{2,15}$ The corresponding values in the MARINA study were +7.2 letters in year 1 and +6.6 in year $2 .{ }^{3}$ In comparison, the current observational study showed that the mean change in visual acuity was +6.8 letters in year 1 and +4.8 letters in year 2 (with a loading phase), with an average of nine injections over a 2 -year period.

Observational studies and outcome data from real-life clinical practice remain limited. The EMR study, a national nAMD database study of ranibizumab in the UK that included information from 11,135 patients (12,951 eyes) and more than 300,000 clinic visits showed that mean visual acuity only improved by +2 letters at the end of year 1 and by +1 letter at the end of year 2 (the mean baseline visual acuity was 55 letters). ${ }^{16}$ However, the median number of visits and injections were similar to those observed in the current study ( 9.2 and five in year 1 and 8.2 and four in year 2, respectively). The differences in the improvement in visual acuity between the present study and the national AMD database study may be attributed to differences in the clinical characteristics of the sites providing data for the two studies and/or the exclusion criteria applied in AURA, as $40.4 \%$ of the cases were excluded from the original screened sample in the present study, contributing to selection bias.

A comparison of the UK results with the other individual countries in the AURA study (Figure 1C) showed notable differences in visual acuity over time, including better outcomes with the UK cohort. In the UK, treatment of nAMD with appropriate imaging is undertaken to specified standards that are agreed with the local National Health Service provider, while in other countries, there may be limits in terms of the numbers of treatments that may be administered, and monitoring may also occur less frequently. The National Institute for Health and Care Excellence criteria ${ }^{17}$ may have also helped select the most appropriate patients for treatment, based on 
guidance TA155, to receive intravitreal anti-VEGF injections: patients must have best-corrected visual acuity between $6 / 12$ and 6/96, with no permanent structural damage to the central fovea. Additionally, the lesion size should be $\leq 12$ disc areas in greatest linear dimension. Royal College of Ophthalmologists clinical guidelines also specify the need for frequent monitoring and appropriate treatment. ${ }^{6}$ UK clinical commissioning groups conduct regular audits, and it is likely that this results in improved adherence with protocols. Consequently, monthly monitoring and relatively frequent treatment are likely to be more prevalent in the UK, resulting in better functional outcomes compared with other countries.

AURA has both strengths and limitations. It was moderately sized, employed a stringent approach to extraction of data (ensuring that all clinical information was captured at every visit), and involved multiple centers, which were geographically dispersed throughout the UK. It may also better reflect real-world outcomes than randomized studies, and could help inform policy and provide benchmarks for UK audits.

Limitations include its retrospective nature, observational design, use of different methods for assessing visual acuity outcomes (although they were standardized), and its conduct between 2009 and 2011; it is likely that with increasing experience of anti-VEGF therapy and the addition of other therapeutic agents, treatment of nAMD will have changed in recent years. A small minority of patients also received other treatments. The study also used an LOCF approach, and thus excluded data from patients with poorer or declining visual outcomes (ie, those who discontinued early due to treatment failure or for reasons not stated). However, observational data (also reported in the global paper) showed a similar pattern in visual acuity outcomes compared with the LOCF analysis. In the UK cohort, visual acuity changed from 55.0 letters $(\mathrm{n}=408)$ at baseline to 62.1 letters $(+7.1)$ at year 1 $(n=263)$ and to 60.8 letters $(+5.8$ letters $)$ at year $2(n=209)$ using observational data (data not shown). Furthermore, only the treated study eye was included. If patients had bilateral disease, then the eye with the worst visual acuity was included into the analysis. In the UK cohort, $20.0 \%$ of patients had bilateral disease.

There are also limitations associated with evaluating the UK subgroup independently of the global population. One of the major drawbacks of the UK AURA cohort is that the 13 centers that were included may not be representative of UK practice as a whole. It is likely that only better-organized centers with excellent record keeping and adequate research staff were recruited to the study. The relatively good results seen with ranibizumab in the UK cohort does not exclude the possibility that results with ranibizumab over the whole of the UK may be closer to those seen in larger real-world studies such as the EMR study, which found that real world outcomes did not match the results in randomized studies. ${ }^{16}$ The ongoing LUMINOUS study (NCT01318941), which includes patients from a larger number of UK centers, may also provide additional information from a real-world perspective.

In summary, visual outcomes in real-life clinical experience in the UK cohort of AURA were only slightly lower than those initially observed in clinical studies such as CATT and MARINA, ${ }^{3,14}$ but there was still some decline over time. This study also showed that anti-VEGF agents are effective in patients with poor baseline visual acuity, which is similar to what was reported in another UK study. ${ }^{18}$ The findings in the UK also highlight the role of the loading phase with ranibizumab treatment. This is consistent with results observed in interventional studies with ranibizumab and bevacizumab. ${ }^{19-21}$ However, the reasons for this are not fully understood, and may be related to a preconditioning effect of the loading phase, resulting in modification of subsequent disease course.

Overall, our results demonstrate that good outcomes are achievable in real-life settings, particularly if high quality control by payers (such as the situation in the UK) means that physicians adhere to protocols for monthly monitoring (including injections being around or above seven in the first year); however, this is associated with high resource utilization and increased burden for patients and health care providers, and may depend on reimbursement. In countries where monitoring and treatment were less frequent, and audits and funding were limited, visual outcomes were poorer and did not reflect the changes seen in clinical studies. Further research into optimal treatment regimens and alternative therapeutic options may help to further improve patient outcomes in real-life settings.

\section{Ethical approval}

Approval from the country-specific independent ethics committees or institutional review boards was received based on the requirements of local law and/or regulations, as follows: UK: NRES Committee North West - Greater Manchester West; France: the authors advise that in France only a data privacy committee is involved, as no institutional review board or ethics committee is involved for observational studies; Canada: The St. Michael's Hospital Research Ethics Board, Institutional Review Board Services (IRB Services), 
University Health Network Research Ethics Board, The University of Western Ontario Research Ethics Board for Health Sciences Research Involving Human Subjects (HSREB); Germany: Ethik Kommission, Medizinische Fakultät Bonn, Biomedizinisches Zentrum, (first approval in Germany); Netherlands: Ethical Committee of Catharina Hospital in Eindhoven; Venezuela: Centro Nacional de Bioética (CENABI), IEC del Hospital Militar, IEC del Centro Médico de Ojos; Italy: Comitato Etico per la Sperimentazione, Ospedale Luigi Sacco, Azienda Ospedaliera - Polo Universitario; Ireland: Research Ethics Committee, Health Service Executive, South East Area (this was the bigger site), Mater Misericordiae University Hospital and Mater Private Hospital Research Ethics Committee.

\section{Acknowledgments}

Medical writing assistance was provided by PAREXEL and was funded by Bayer HealthCare Pharmaceuticals AG.

AURA was funded by Bayer HealthCare Pharmaceuticals AG.

This work was presented in part at the Royal College of Ophthalmologists Annual Congress, Birmingham, UK, May 20-22, 2014.

The following principal investigators were members of the AURA Study Group (UK): Clare Bailey, Susan Downes and the Oxford clinical research team, Jon Gibson, Javeed Khan, Geeta Menon, James Talks, and Deepali Varma.

\section{Disclosure}

Philip Hykin has received grants from Bayer HealthCare, Allergan, and Novartis and acts as a consultant to Bayer HealthCare, Novartis, and Allergan; he has also received support for travel to meetings, support for participation in review activities, and provision of writing assistance, medicines, equipment, and administrative support from Bayer HealthCare; payment for lectures from Allergan and Novartis; and support for conference attendance. Usha Chakravarthy has attended advisory boards and received honoraria from Allergan, Bayer, Novartis, and Roche. Andrew Lotery has received educational grants from Bayer HealthCare and Novartis and acts as a consultant to Bayer HealthCare, Novartis, and Allergan; he has also received support for conference attendance from Bayer HealthCare and Novartis. Martin McKibbin has received honoraria from Alcon and has received support for conference attendance from Bayer HealthCare and Novartis; an application for funding for an investigator-initiated study to Alcon was also successful. Jackie Napier is an employee of Bayer HealthCare
Pharmaceuticals AG. Sobha Sivaprasad has received grants from Bayer HealthCare, Allergan, and Novartis and acts as a consultant to Bayer HealthCare, Novartis, and Allergan. She has also received support for travel to meetings, participation in review activities, and provision of writing assistance, medicines, equipment, or administrative support from Bayer HealthCare and Novartis; payment for lectures from Bayer HealthCare, Allergan, and Novartis; and support for conference attendance. The authors report no other conflicts of interest in this work.

\section{References}

1. Ablonczy Z, Dahrouj M, Marneros AG. Progressive dysfunction of the retinal pigment epithelium and retina due to increased VEGF-A levels. FASEB J. 2014;28(5):2369-2379.

2. Brown DM, Kaiser PK, Michels M, et al. Ranibizumab versus verteporfin for neovascular age-related macular degeneration. $N$ Engl J Med. 2006;355(14):1432-1444.

3. Rosenfeld PJ, Brown DM, Heier JS, et al. Ranibizumab for neovascular age-related macular degeneration. $N$ Engl J Med. 2006;355: 1419-1431.

4. Sadda SR, Stoller G, Boyer DS, Blodi BA, Shapiro H, Ianchulev T. Anatomical benefit from ranibizumab treatment of predominantly classic neovascular age-related macular degeneration in the 2-year anchor study. Retina. 2010;30(9):1390-1399.

5. Lucentis ${ }^{\circledR}$ (ranibizumab injection) [prescribing information]. San Francisco, CA, USA: Genentech, Inc.; 2014.

6. The Royal College of Ophthalmologists. Age-related macular degeneration: guidelines for management. The Royal College of Ophthalmologists website. Available from: http://rcophth-website. www.premierithosting.com/docs/publications/2009-SCI-014_AgeRelated_Macular_Degeneration.pdf. Accessed August 18, 2014.

7. Regillo CD, Brown DM, Abraham P, et al. Randomized, double-masked, sham-controlled trial of ranibizumab for neovascular age-related macular degeneration: PIER Study year 1. Am J Ophthalmol. 2008;145(2): 239-248.

8. Schmidt-Erfurth U, Eldem B, Guymer R, et al. Efficacy and safety of monthly versus quarterly ranibizumab treatment in neovascular agerelated macular degeneration: the EXCITE study. Ophthalmology. 2011; 118(5):831-839.

9. Boyer DS, Heier JS, Brown DM, Francom SF, Ianchulev T, Rubio RG. A Phase IIIb study to evaluate the safety of ranibizumab in subjects with neovascular age-related macular degeneration. Ophthalmology. 2009; 116(9):1731-1739.

10. Hariprasad SM, Morse LS, Shapiro H, Wong P, Tuomi L. Fixed monthly versus less frequent ranibizumab dosing and predictors of visual response in exudative age-related macular degeneration. J Ophthalmol. 2012; 2012:690641.

11. Busbee BG, Ho AC, Brown DM, et al. Twelve-month efficacy and safety of $0.5 \mathrm{mg}$ or $2.0 \mathrm{mg}$ ranibizumab in patients with subfoveal neovascular age-related macular degeneration. Ophthalmology. 2013; 120(5):1046-1056

12. Holz FG, Amoaku W, Donate J, et al. Safety and efficacy of a flexible dosing regimen of ranibizumab in neovascular age-related macular degeneration: the SUSTAIN study. Ophthalmology. 2011;118(4):663-671.

13. Holz FG, Tadayoni R, Beatty S, et al. Multi-country real-life experience of anti-vascular endothelial growth factor therapy for wet age-related macular degeneration. Br J Ophthalmol. 2015;99(2):220-226.

14. Comparison of Age-related Macular Degeneration Treatments Trials (CATT) Research Group; Martin DF, Maguire MG, Fine SL, et al. Ranibizumab and bevacizumab for treatment of neovascular age-related macular degeneration: two-year results. Ophthalmology. 2012;119(7):1388-1398. 
15. Brown DM, Michels M, Kaiser PK, et al. Ranibizumab versus verteporfin photodynamic therapy for neovascular age-related macular degeneration: two-year results of the ANCHOR study. Ophthalmology. 2009;116(1):57-65.

16. Writing Committee for the UK Age-Related Macular Degeneration EMR Users Group. The neovascular age-related macular degeneration database: multicenter study of 92,976 ranibizumab injections: report 1: visual acuity. Ophthalmology. 2014;121(5):1092-1101.

17. National Institute for Health and Care Excellence. Ranibizumab and pegaptanib for the treatment of age-related macular degeneration. National Instutute for Health and Care Excellence website. Available from: http://www.nice.org.uk/Guidance/TA155. Accessed August 18, 2014.

18. Shona O, Gupta B, Vemala R, Sivaprasad S. Visual acuity outcomes in ranibizumab-treated neovascular age-related macular degeneration; stratified by baseline vision. Clin Experiment Ophthalmol. 2011;39(1): $5-8$.
19. Menon G, Chandran M, Sivaprasad S, Chavan R, Narendran N, Yang Y. Is it necessary to use three mandatory loading doses when commencing therapy for neovascular age-related macular degeneration using bevacizumab? (BeMOc Trial). Eye (Lond). 2013;27(8):959-963.

20. Niwa Y, Sawada O, Miyake T, et al. Comparison between one injection and three monthly injections of intravitreal bevacizumab for myopic choroidal neovascularization. Ophthalmic Res. 2012;47(3): $135-140$.

21. Bolz M, Simader C, Ritter M, et al. Morphological and functional analysis of the loading regimen with intravitreal ranibizumab in neovascular age-related macular degeneration. Br J Ophthalmol. 2010;94(2): $185-189$. 


\section{Supplementary material}

RPFV $=$
$\begin{gathered}\text { FPFV } \\ \text { January } 1,2009 \quad \text { August 31, } 2009\end{gathered}$

Figure SI Timeline for study design.

Abbreviations: FPFV, first patient, first visit; LPFV, last patient, first visit; LPLV, last patient, last visit; VEGF, vascular endothelial growth factor.

\section{Publish your work in this journal}

Clinical Ophthalmology is an international, peer-reviewed journal covering all subspecialties within ophthalmology. Key topics include: Optometry; Visual science; Pharmacology and drug therapy in eye diseases; Basic Sciences; Primary and Secondary eye care; Patient Safety and Quality of Care Improvements. This journal is indexed on
PubMed Central and CAS, and is the official journal of The Society of Clinical Ophthalmology (SCO). The manuscript management system is completely online and includes a very quick and fair peer-review system, which is all easy to use. Visit http://www.dovepress.com/ testimonials.php to read real quotes from published authors. 